\title{
A Review on Traditional Architecture Houses in Buddhist Culture
}

\author{
Sonam Chuki ${ }^{1,2}$, Raju Sarkar ${ }^{1,2,3, *}$, Ritesh Kurar ${ }^{3}$ \\ ${ }^{1}$ College of Science and Technology, Royal University of Bhutan, Rinchending, Bhutan \\ ${ }^{2}$ Center for Disaster Risk Reduction and Community Development Studies \\ ${ }^{3}$ Delhi Technological University, Bawana Road, Delhi, India \\ *Corresponding author: rajusarkar.cst@rub.edu.bt, rajusarkar@dce.ac.in
}

\begin{abstract}
The vernacular architecture of a country reflects its culture, religion and identity. Researchers found that countries with similar culture and religion share few similar architectural characteristics. The most similar characteristic is the choice of building material used, where locally available materials such as earth, wood and bamboo are found to be used extensively. This paper explores the traditional architecture houses of few Asian countries with Buddhist culture viz. Bhutan, China, Japan, Laos, Myanmar, Nepal, Thailand and Vietnam; mainly focusing on its vernacular dwellings. The architectural features, organization of spaces and building materials of vernacular dwellings of these countries are also exploited.
\end{abstract}

Keywords: buddhist culture, traditional houses, vernacular dwellings, traditional architecture

Cite This Article: Sonam Chuki, Raju Sarkar, and Ritesh Kurar, "A Review on Traditional Architecture Houses in Buddhist Culture." American Journal of Civil Engineering and Architecture, vol. 5, no. 3 (2017): 113-123. doi: 10.12691/ajcea-5-3-6.

\section{Introduction}

Traditional architecture of a country reflects its religious as well as cultural beliefs, therefore, it is an important identifying feature of a country and its people. Traditional Bhutanese architecture is believed to have existed for many centuries with the oldest buildings dating back to $7^{\text {th }}$ century. It not only satisfies the functional and economical needs but also the social and spiritual requirements. In traditional Bhutanese architecture, there is generally no planning and designing done on paper before a structure is built and nails are not used, the wooden pieces of the framework are assembled by the dove-tail technique. Similar unique feature can also be seen in the traditional dwellings of other Asian Buddhist countries such as Japan, Nepal and Vietnam where tenonmortise connection is used in the wooden framework instead of metal fasteners such as nails.

Another similar feature shared by the vernacular dwellings of such Asian countries is the use of rectilinear forms as a respect to the traditional architecture since in Buddhism, straight lines represents purity, focus and determination. Wooden surfaces such as beams, windows and doors and the walls of traditional dwellings of Bhutan are normally painted with various symbols, each with a special religious significance. The explicit paintings of Phallus can be seen painted on the walls of traditional houses which is believed to drive away evil eye and malicious gossip [1]. However, the decorative elements are comparatively less in other such Buddhist countries such as Myanmar where the only decorative elements found in its traditional houses are in the door and window leaves and veranda handrails.

The floor of traditional dwellings in Vietnam, Thailand, Myanmar, Laos, Japan and China are found to be raised at a certain height above the ground to avoid pests, flood and for ventilation. However, in Buddhist culture the elevated or raised floor reflect its religious beliefs where such elevated space expresses higher value of mind [2].

Zones and steps indicate hierarchy in traditional architecture which reflects the existing hierarchy system in the Buddhist society [2]. The spaces in the vernacular dwellings of Bhutan are designed to be functional with each level of the house having distinctive functions. The traditional dwellings usually comprise of two stories and sometimes three stories with an open attic which is used for drying and storing food. The division of spaces have been based on a vertical hierarchy where the ground floor is used as a cowshed and storage, furthermore, the main living spaces are in the first floor with sacred space (altar) on the highest level. Removable wooden exterior staircase leads to the first floor of the house. Such similar staircase is found in traditional houses of Myanmar, Thailand, Laos and Vietnam to access the elevated space. The cowshed in the ground floor and the space in the attic for storing and drying the agricultural products reflect the country's agrarian society.

Roof is the most important feature of the traditional architecture as it represents the highest level of the hierarchy system in Buddhist culture [3]. The countries with Buddhist culture have similar open high-pitched roof with deep eaves as a climatic response to the heavy rainfall. To prevent the earth walls and timber structures from the heavy monsoon rain, wide roof overhangs have been provided. However, according to the religious and 
cultural beliefs, the high-pitched feature gives the roof an appearance of almost touching the sky, thus, making the roof a connection between heaven and earth [2].

\section{Materials Used for Construction of Traditional Dwellings}

\subsection{Timber}

The most common feature of vernacular dwellings of the Asian countries with Buddhist culture is the choice of the building material. Timber is the most important feature of traditional architecture of these countries as it makes up most part of the traditional dwellings. In Bhutan, wood is extensively used for windows, doors, rabsels, cornices, flooring, roof truss and structural framework [3]. Similar uses of timber in windows, doors, framework and flooring can be seen in Vietnam [4], Laos [5], Japan [6], Myanmar [7], Thailand [2] and some regions of China [8] and Nepal [9]. Wooden framework is the fundamental element of traditional architecture of these countries, however, the houses of countries such as Vietnam, Laos, Myanmar and Thailand use wood for wall construction as well. Wooden shingles are found to be used as roofing material for the traditional houses of these countries along with thatch roof of straw and leaves.

\subsection{Earth}

Rammed earth construction is famous in the western part of Bhutan. In the colder regions of China; which is about $417.4 \times 10^{4} \mathrm{~km}^{2}$, approximately $43.5 \%$ of the country's land area [10]; one of the main styles of vernacular dwellings is cave dwelling which dates to the Neolithic age [8]. The thermal mass provides insulation to the interior of the cave houses. Similar earth construction called "Tolou" which is made up of mud walls can be seen in hot summer and cold winter region of China [8].

\subsection{Bamboo}

Bamboo and timber have identical uses in traditional houses of these countries. In Bhutan, bamboo is mainly used in Shamig/Ekra. The Shamig panel is an element, traditionally built with mud plaster over a bamboo mat inserted between timber frames [11]. Similar bamboo wall construction can be seen in countries like Myanmar [7], Laos [5], Japan [12] and some regions of China [8].

\subsection{Stone}

In Bhutan, stone is used for wall construction of the traditional dwellings as well as the religious structures [3]. The traditional houses with stone masonry are mainly found in the central and eastern Bhutan.

\subsection{Rice Paper}

Rice paper is a traditional paper made from paper mulberry plant and has been used for centuries in China, Japan, and Vietnam for writing, artwork, and architecture. In Japanese architecture, rice paper is used in fusuma and shoji. A typical Japanese room in traditional Japanese houses is made up of fusuma, shoji and tatami straw mats. Fusuma is a vertical rectangular panel which slides from side to side and acts as a door. Shoji is a door, window or room divider which consists of translucent paper over a wooden frame. The paper panels in fact can be completely opened allowing for cross ventilation [12].

\section{Literature Review}

Shah [13] has done a research on regionalism and Nepalese architecture. In the research, Shah has explained that architecture is a product of climate, socio-cultural background and religion, due to which no two countries will have the exact identical architecture even if they fall within the same region. In the research, he studied the architectural features of the three regions of Nepal Himalayan region, the midland region and the Terai region. The architectural style of the Himalayan region is mainly influenced by the Buddhist culture from Tibet across the border to the north.

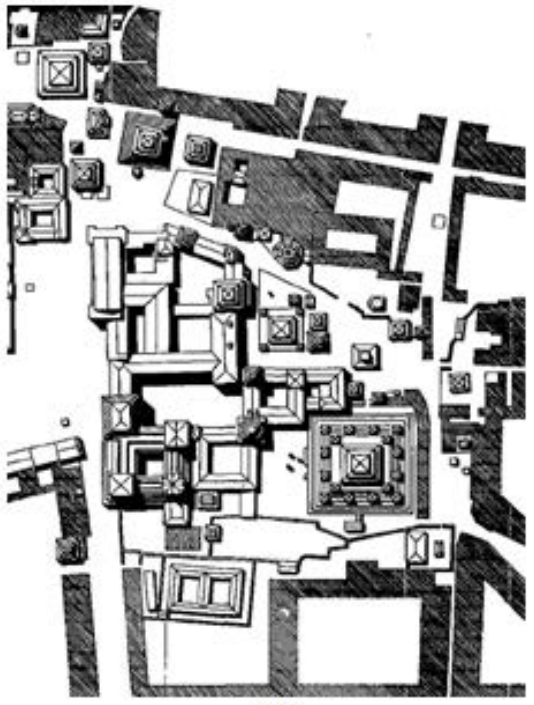

(a)

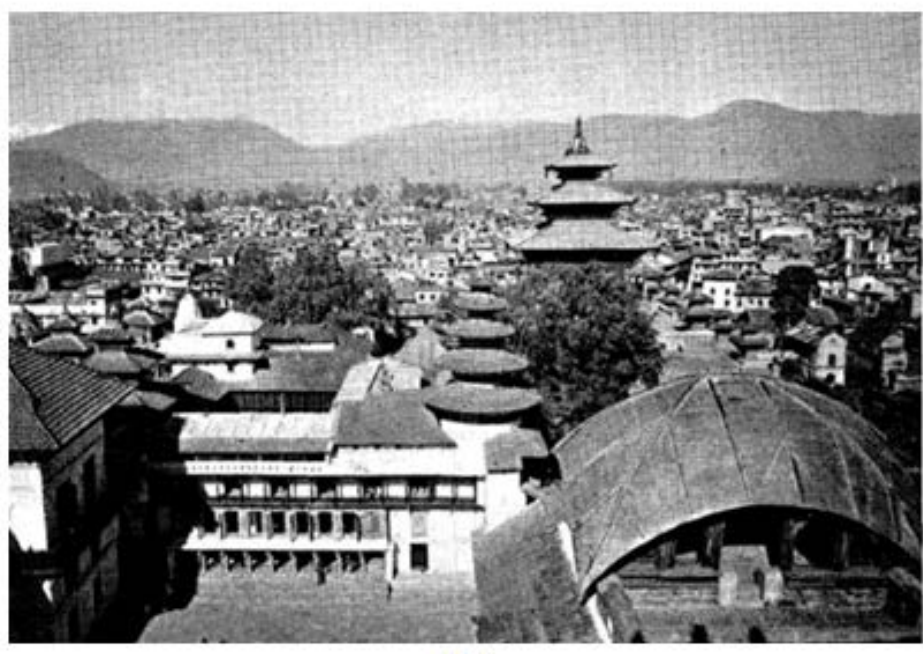

(b)

Figure 1. (a) Durbar square area and (b) Settlement pattern of Kathmandu city core [13] 
As per the research, the capital city of Nepal, Kathmandu lies in the midland region and is home of two religious communities (Hinduism and Buddhism). The towns of the Kathmandu valleys as shown in Figure 1 are defined by the religious architectural features such as temples, Chaityas and Viharas. The houses consist of small courtyards, closely spaced with narrow streets and uniformly built of burnt and unburnt clay bricks and such compact settlements aremidd known as Newar settlements. In the research, it has been observed that there seems to be no uniqueness in the culture, art and architecture of the Terai region and it has a similar architecture derived from Indo-Aryan people of northern India. In conclusion, Shah mentioned that advancement of building technologies has resulted in the importance of vernacular architecture being curtailed, where, accepting all the new developments just in the name of modernism might result in identity problem in the future.

D'Ayala and Bajracharya [9] in their research on traditional Nawari house in Kathmandu valley, have studied the planning and architectural aspects, construction and materials, along with the seismic vulnerability of the traditional Newari house in Kathmandu valley. As per the research, these buildings are typically found in flat terrain and are mainly found in the royal cities of Kathmandu, Lalitpur and Bhaktapur. This construction type is nonengineered and has been in practice for more than 200 years. The type of building materials used in this type of houses is shown in Table 1 . In the research, it is found that the traditional Newari house usually has a typical rectangular plan and consists of three stories, additionally, these buildings are consisting of timber frame called Dalan as shown in Figure 2. For these types of houses external masonry walls play the role of lateral load resisting system as well as the gravity load-bearing system. The authors further studied about the foundation, floor system (Figure 2) of such traditional Newar houses. In the research, D’Ayala and Bajracharya also extensively explored and analyzed the seismic vulnerability of the traditional Newar houses and it is summarised in Table 2.

Sdei [12] in his research on thermal comfort in traditional Japanese houses extensively studied how the traditional Japanese houses made up of traditional materials like timber, bamboo and rice paper and with no thermal insulation can become a comfortable shelter during the cold winters and hot humid summers. In the research, the author presented the analyses and results based on the summer and winter measurements of a theoretical model by monitoring three traditional Japanese houses. Researcher developed a simple model with a south facing room which was evaluated using a thermal simulation software program for the two critical seasons (winter and summer) and with and without veranda. From the results of the modeling process, he found that in winter the internal and external temperature differ up to $8.7^{\circ} \mathrm{C}$ during the day and up to $5.46^{\circ} \mathrm{C}$ during the night as shown in Figure 3. The inhabitants can therefore achieve thermal comfort by layering up (using thick cloths) and using small objects to heat their bodies. However, in the summer, according to the research he concluded that there is no difference between the ambient and internal air temperature due to the high ventilation rate provided by the movable paper panels which allow the surrounding air to flow freely throughout the house.

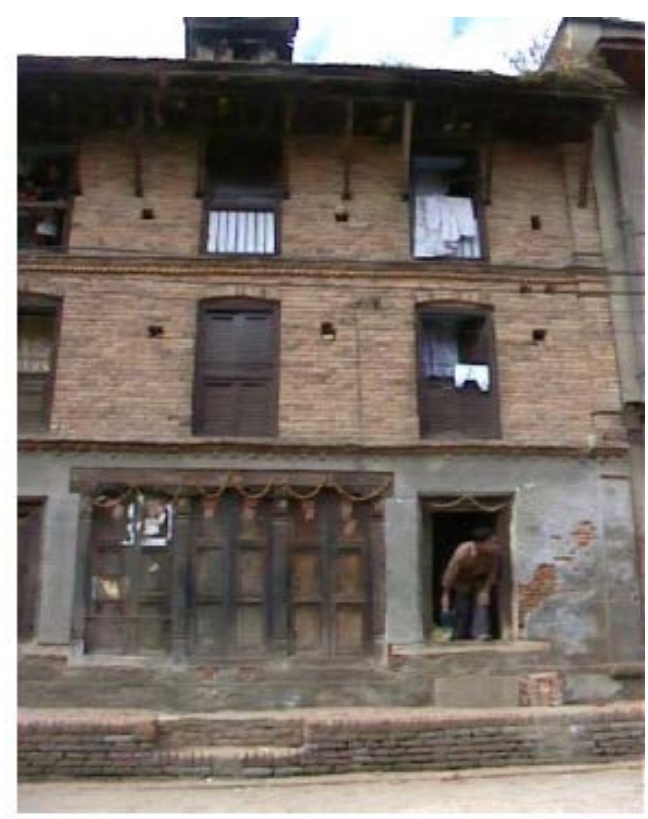

Figure 2. (a) Typical urban house with dalan at ground floor level [9]

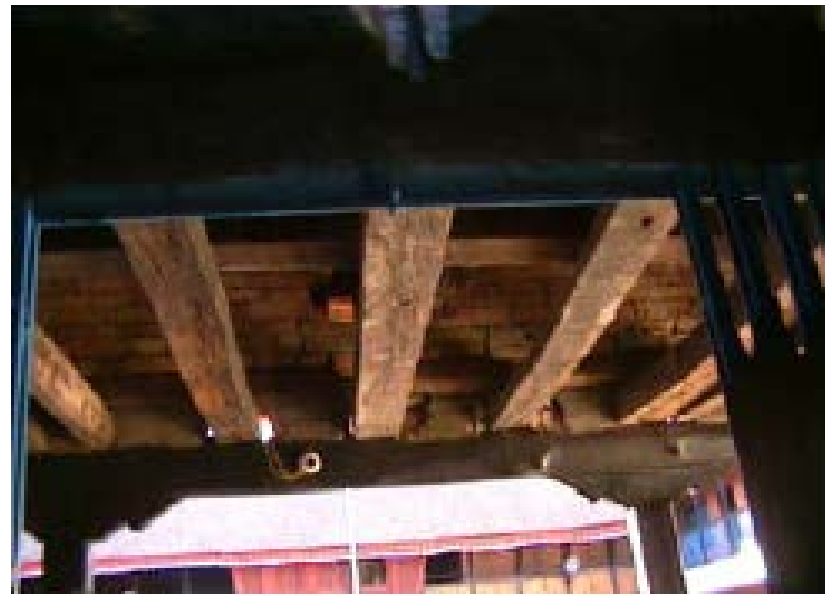

Figure 2. (b) Typical floor structure [9]

Table 1. Structural element and building materials of Newari house [9]

\begin{tabular}{|l|l|}
\hline Structural element & Building materials \\
\hline Walls & $\begin{array}{l}\text { Brick bonded with mud mortar forming ordinary masonry. Typically, two types of bricks are used; ordinary sun-dried bricks of } \\
\text { dimensions } 21 \text { x } 105 \text { x } 50 \mathrm{~mm} \text {, and fired bricks called "dachi aapa” with the same dimensions and trapezoidal cross section; so } \\
\text { that the mud bed-joint is partially covered externally by the brick. }\end{array}$ \\
\hline Frames & $\begin{array}{l}\text { The timber frame is made up of tin columns, surmounted by a capital upon which sits a double beam. Adjacent timber frames } \\
\text { are usually connected only at the level of the beam. The columns usually have a square cross section and are pinned on the } \\
\text { ground, } 100 \text { to } 150 \text { mm apart. }\end{array}$ \\
\hline Roof and floor & $\begin{array}{l}\text { Timber joists run from wall to wall at closely spaced intervals of } 150 \text { to } 200 \text { mm. above the joists either planks or a bamboo } \\
\text { chirpat are covered by the compressed mud. }\end{array}$ \\
\hline
\end{tabular}


Table 2. Seismic strenghtening provisions [9]

\begin{tabular}{|l|l|}
\hline Seismic Deficiency & Description of seismic strengthening provisions used \\
\hline Connection between walls & Use of steel ties at floor levels to connect front and back walls has been proposed. \\
\hline Flexible diaphragm & $\begin{array}{l}\text { Inclusion of diagonal ties within the inferior floor structure to stiffen the floor structure and create a more rigid diaphragm } \\
\text { has been proposed. }\end{array}$ \\
\hline
\end{tabular}

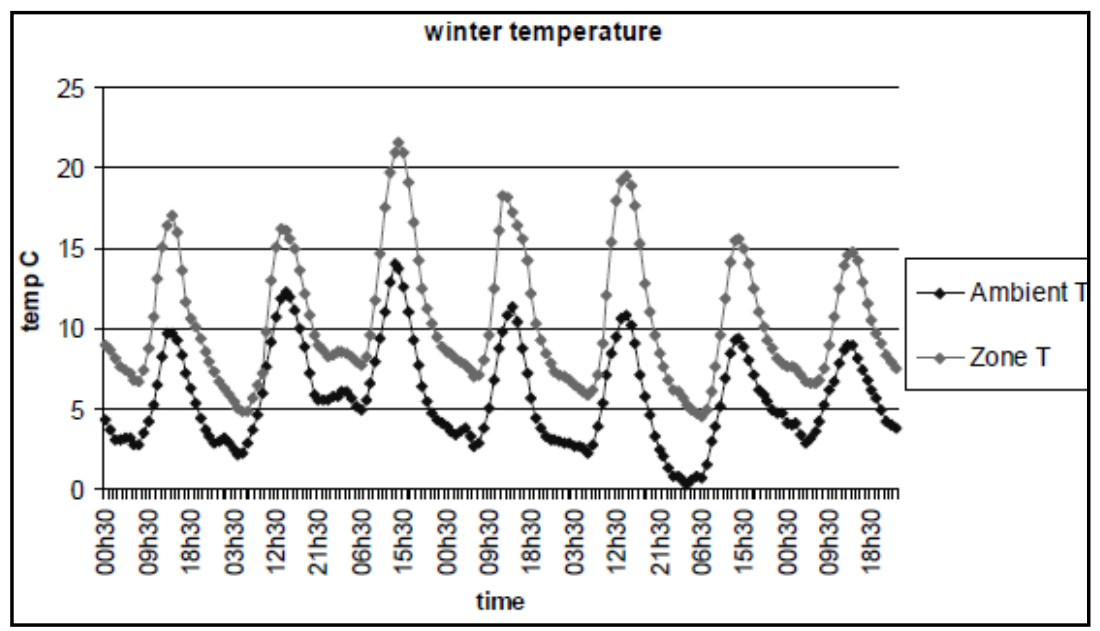

Figure 3. External and Internal temperature difference [12]

Satoshi [6] conducted a research on the tradition of wooden architecture in Japan. As per the research, wooden post and beam structure is known to be the basic characteristic of Japanese architecture where a joinery system (mostise-and-tenon connections) is used to join the structural members along with wooden pegs and wedges to secure the joints. This type of structure is reversible which means that it can be disassembled and reassembled without damaging the members, where, the structure is not hidden within the walls but instead exposed to express the beautiful traditional forms and patterns. Satoshi concludes that in Japan, since wood is the most essential building material used by its vernacular architecture, carpentry and craftsmanship play a vital role and the need for the Japanese carpenters to develop their craftsmanship to a high degree of perfection is a necessity.

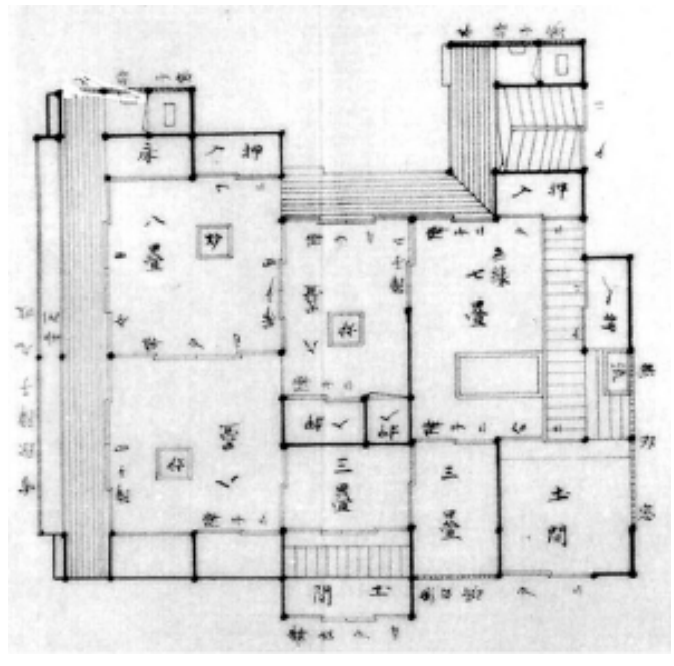

Figure 4. (a) Planning layout of Sapporo [14]

Choi [14] in his research on scales and meanings of Japanese urbanism and architecture in Sapporo, studied the urbanism and architecture created in Sapporo by
Kaitakushi in the 1870s. The houses built for the Kaitakushi officials show side by side placement of the Japanese and non-Japanese framework in contrast to a traditional Japanese house. As per the research, the planning and building of early structures in Sapporo coincided with the time when notions of modern Japan have been created. Based on the research, the planning layout of Sapporo, as shown in the Figure 4(a)-(b), are neither completely Japanese nor American. The first capital of Hokkaido is, therefore, a hybrid. The city of Sapporo had a grid layout which bore some resemblance to the cities of the American west such as Salt Lake City.

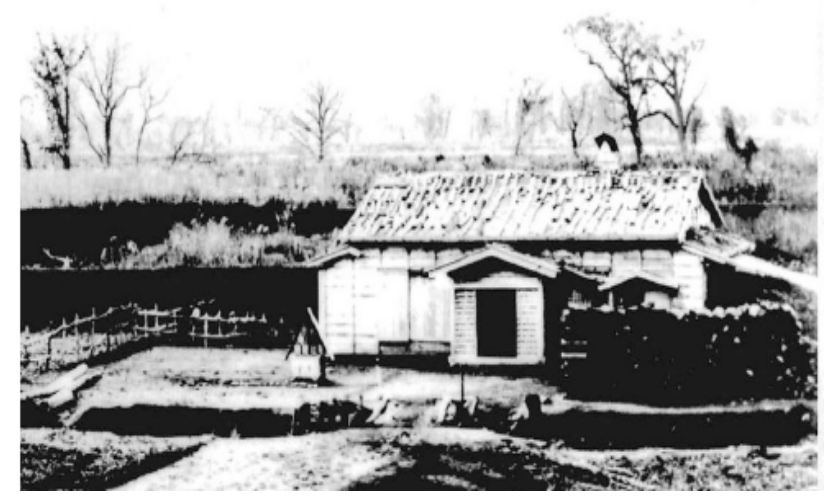

Figure 4. (b) Conventional Japanese house [14]

Antarikananda et.al [15] attained lessons from traditional architecture by studying designs for a climatic responsive contemporary house in Thailand. They analyzed the design characteristics of the traditional Thai house which could be applied in the contemporary house in order to improve the occupants' comfort and minimize energy consumption. In the research, they investigated the thermal performance of traditional and contemporary buildings in the selected three regions (south, central and 
north-eastern) of Thailand using a simulation model and based on the building form and materials. Figure 6 and shows the traditional house in the three regions selected to be compared with the contemporary house in the regions. Figure 7 shows an improved contemporary Thai house design which has incorporated the design features of traditional Thai houses. Based on the evidence from the study, Antarikananda et.al, concluded that the traditional house designs are superior to the contemporary in providing thermal comfort for all three selected climatic zones of Thailand.

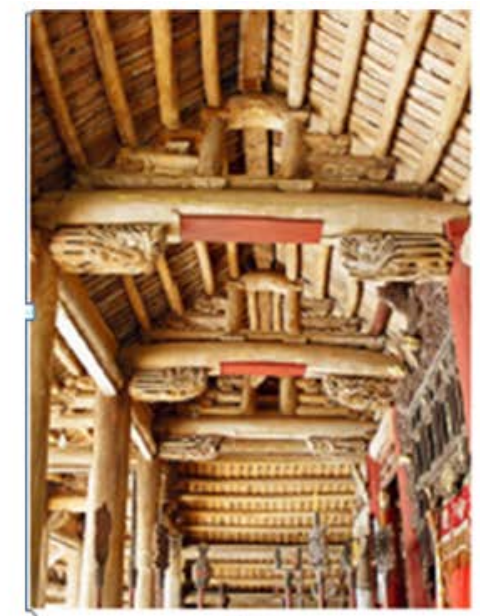

(a)

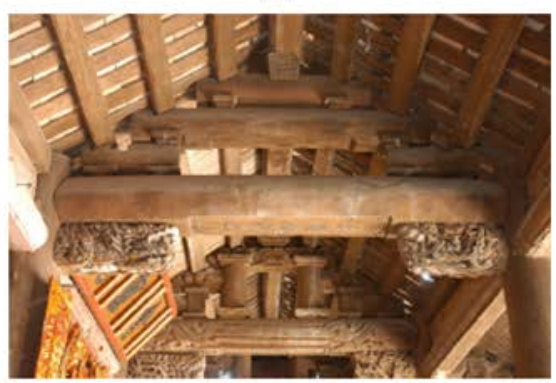

(b)

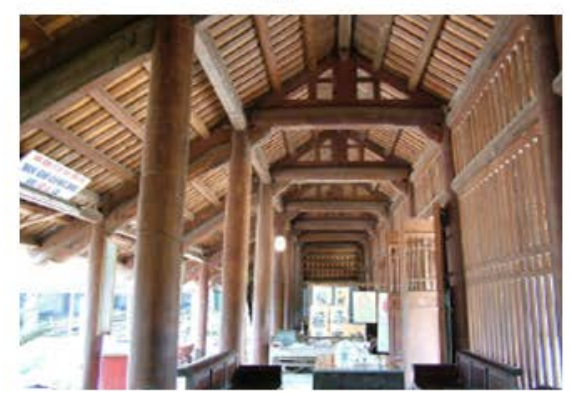

(c)

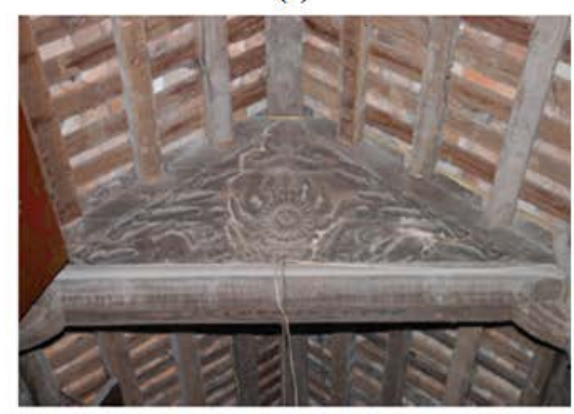

(d)

Figure 5. (a) Bell Hanger-Type I and (b) Beam Pilling-Type II, (c) Keo-Type III and (d) Van me- Type IV [4]

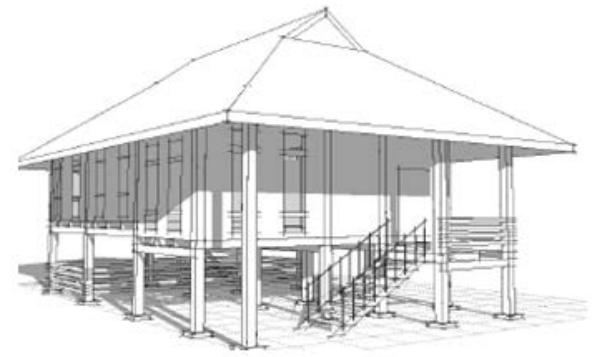

(a)

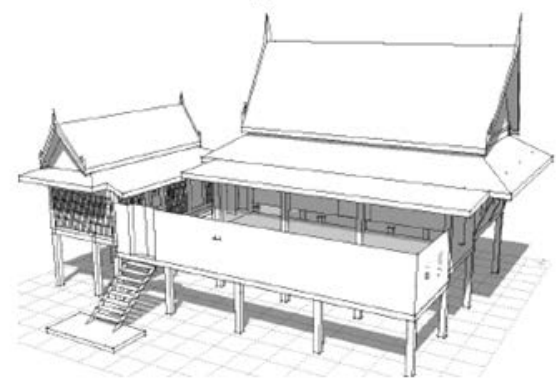

(b)

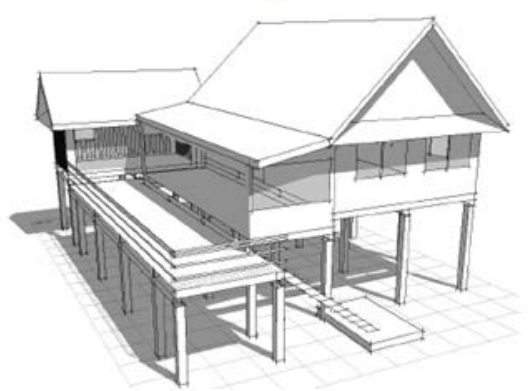

(c)

Figure 6. Traditional Thai house (a) South region, (b) Central region and (c) North-east region of Thailand [15]

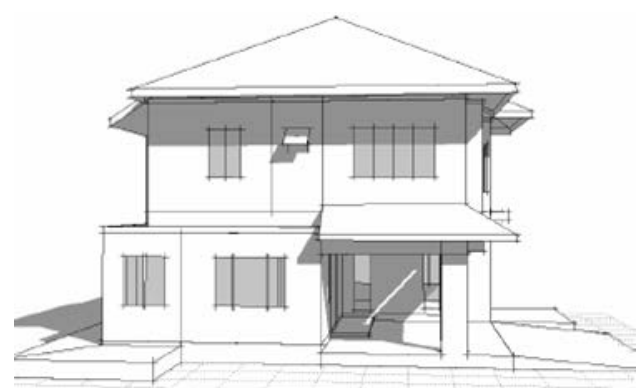

(a)

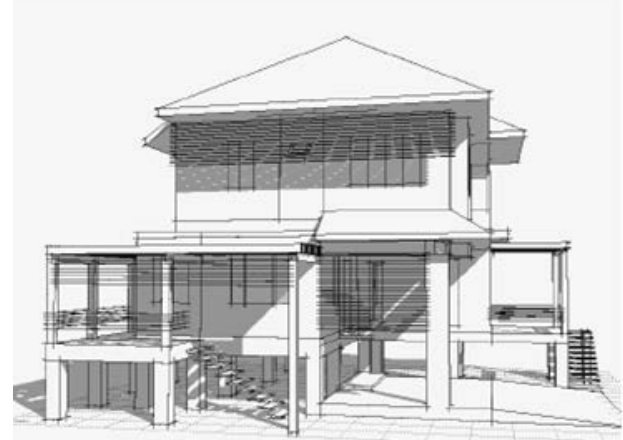

(b)

Figure 7. (a) Inadequate shading on west façade of a contemporary house in the central region at 3pm in June and (b) An improved contemporary design featuring additional shading, raised floors and shaded external platforms (right) [15] 


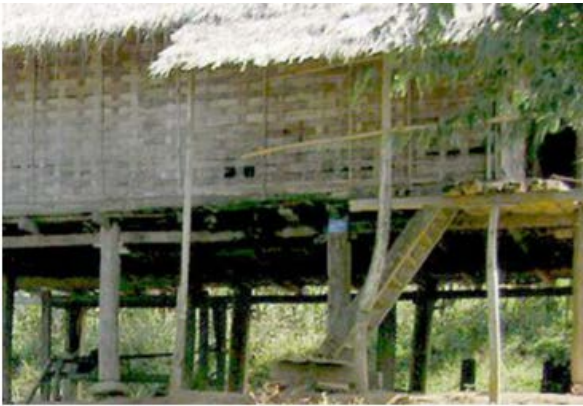

(a)

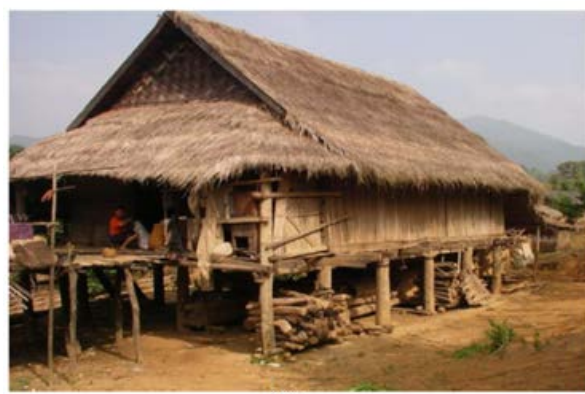

(b)

Figure 8. (a) A typical house design for poor households and (b) small middle class household in Namo Nua village [5]

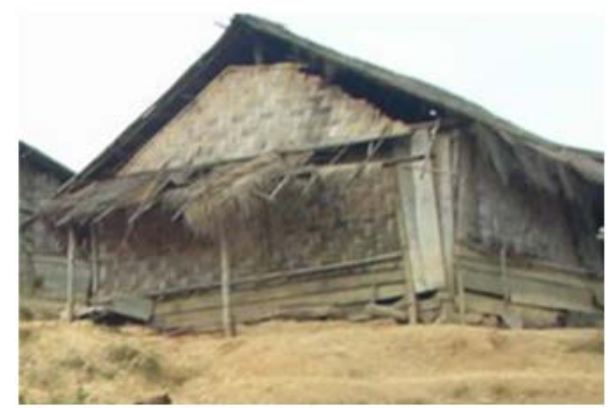

(a)

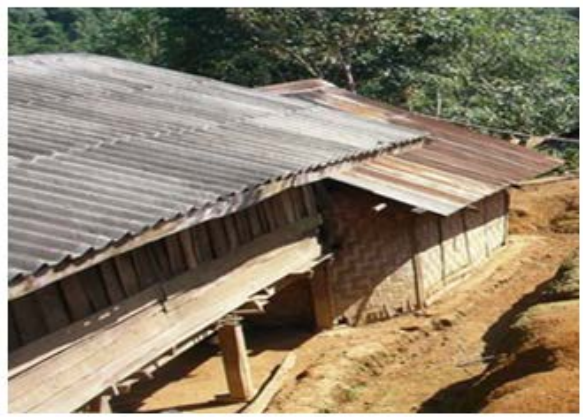

(b)

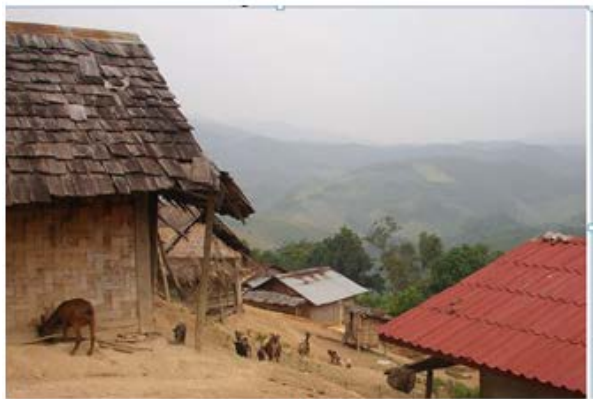

(c)

Figure 9. (a) Poor household, (b) middle class household and (c) type of roofs [5]
Kretz [5] has done a research on traditional housing in northern Laos - wood preferences and impact on the forest diversity. In the research, two villages (Namo Nua and Phou Xan) with different ethnicity and wealth standards, in northern Laos have been selected. According to the research, in the village Namo Nua, construction skills and knowledge about timber is given utmost importance. Namo Nua villagers build their houses (Figure 8) on high poles, several meters over the ground, and use varied tree species in their constructions. Leaf from rattan or grass are used as roof. As per the research, the largest houses consisted roughly of one tree for the walls and one tree to the floor. Only a few nails are used in the construction, as it is built to be fixed together like a puzzle. The houses in Phou Xang are generally small and made simple (Figure 9). The design depends on wealth class, available construction material, technology and traditions.

Most people in Phou Xang build their houses on the ground and use fewer tree species. They use the soil as the floor. In the paper, Kretz explained that new and modern materials are more frequently used in the house constructions such as sheeted metal roof which is used instead of wood, grass or bamboo roof (Figure 9). In conclusion, it has been explained that the tradition of using wood as the main building material in these two villages have resulted in extensive forest degradation and the unsustainable way of wood harvest has led to the extinction of important construction wood.

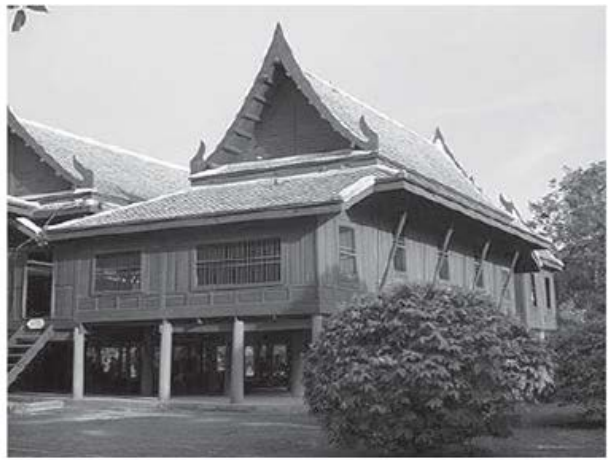

(a)

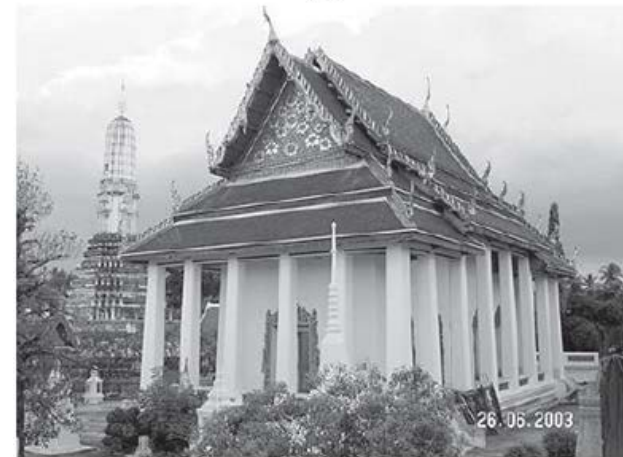

(b)

Figure 10. (a) Residential building and (b) Religious building [2]

Chitranukroh and Buranakarn [2] studied on sentiment in traditional Thai architecture. In their research, they analyzed the spiritual aspect of traditional Thai architecture using the systems method. The authors divided the traditional architecture of Thailand into two 
categories viz. traditional houses and religious buildings (Figure 10). The traditional Thai houses are chiefly characterized by a high-pitched roof made of grass, thatch and straw and raised floors intended to prevent pests and flood and provide insulation. Thick brick walls used to achieve thermal comfort due to its thermal performance. The other major materials include wood, masonry and thatch. As per the research, the raised floor of the house expresses higher value of mind and zones and steps in traditional architecture indicates the hierarchy system in the society. The authors concluded that the incorporation of nature in the design and use of natural building materials make Thai architecture more environmental friendly.

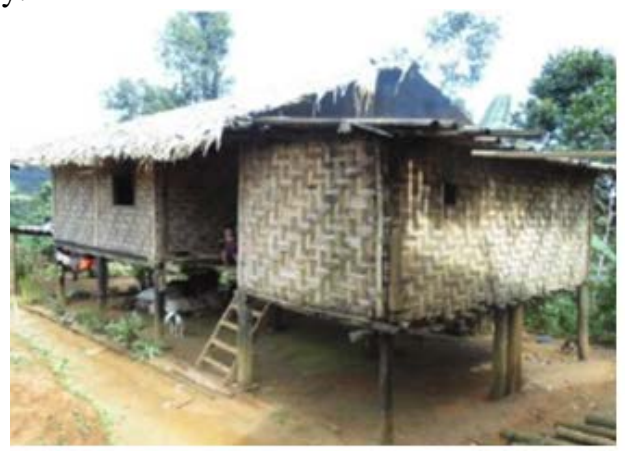

(a)

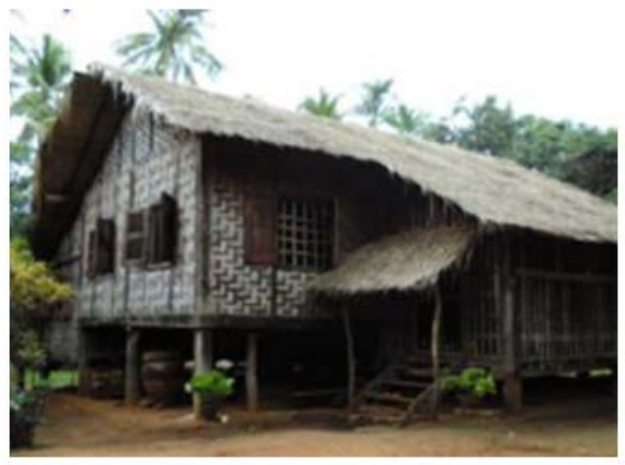

(b)

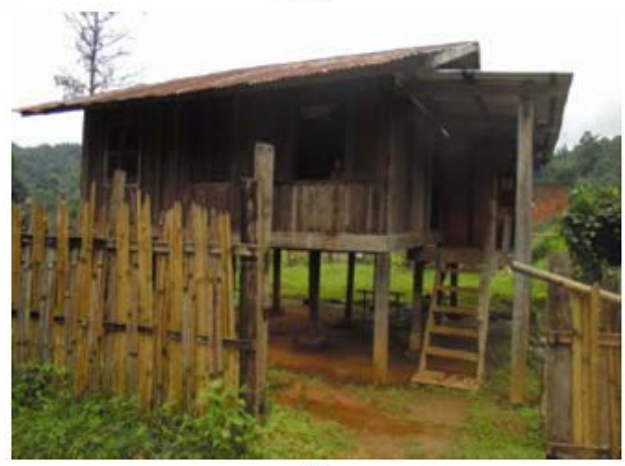

(c)

Figure 11. North East view of (a) Sagaw Kayin, (b) Paw Kayin, and (c) Bwe Kayin houses [7]

Virginia et.al [7] did a research on Kayin traditional houses in Myanmar. In their research, they studied and analyzed the characteristics of traditional houses in Kayin of Myanmar which has tropical climatic conditions. As per the research, the Kayin houses are characterized by bamboo and timber structure which is raised about six to eight feet above the ground with removable ladder and are less in windows. As per the research, the whole group of Kayin houses can be divided into three main sets (Sagaw, Paw and Bwe). The sagaw houses are rectangular or square in plan and they place their ladder at the east and west orientation only and they always include a veranda (Figure 11(a)). The Paw Kayin houses have unsymmetrical plan and always include decking area in the house (Figure 11(b)). While the Bwe Karin houses are of informal balance form and they always place their ladder in center of the house (Figure 11(c)). After studying and analyzing these houses, the authors have provided some suggestions such as need for provision of proper shading, adequate doors and windows for natural lighting and ventilation, as well as, provision of handrails for all the stairs and veranda for safety.

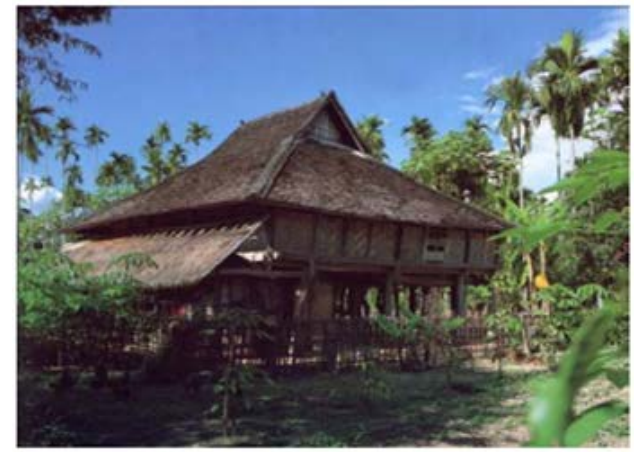

(a)

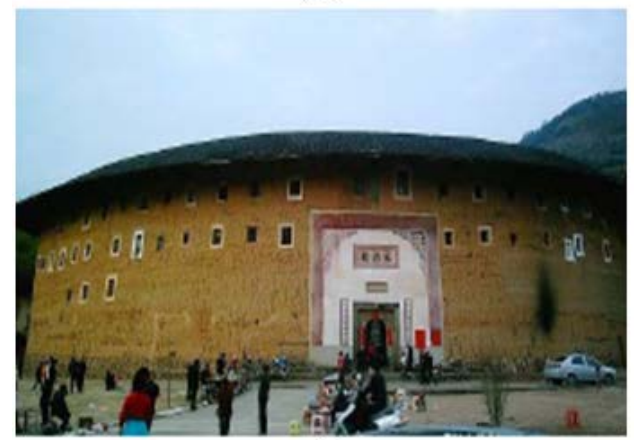

(b)

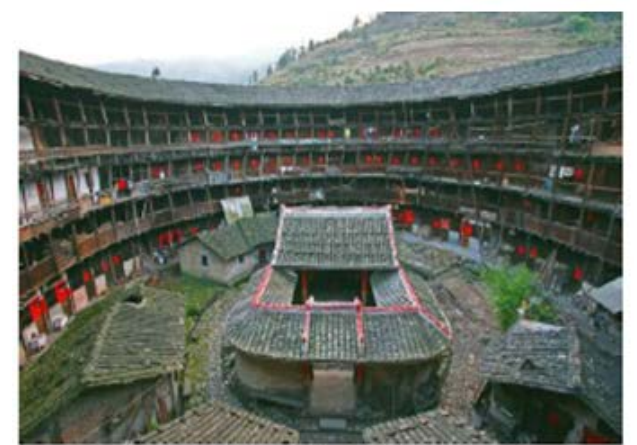

(c)

Figure 12. (a): Wooden storied house, (b) Tolou building exterior view, and (c) Tolou building courtyard [8]

Sun [8] in the research on Chinese climate and vernacular dwellings, explored and studied the climatic response of vernacular dwellings in the regions viz. severe cold region, cold region, moderate region, hot summer and cold winter region, and hot summer and mild winter region for adopting climate-responsive experiences into current residential development. As per the research, in 
severe cold region, people constructed south facing low rise houses with mud walls and with spacious courtyards to obtain sufficient solar access throughout the structure. Sun explains that the type of dwelling found in the moderate region is mainly of timber construction which consists of a small structure with three to five rooms (Figure 12(a)). Other features include bamboo and wooden frames, steep thatched roofs, sloping eaves and wide-open corridors. As per the research, the type of dwelling found is in hot summer and cold winter region is called tolou (clay building) as shown in Figure 12 (b)-(c). This type of building is made up of mud walls with several stories high covered by tiled roofs with wide overhanging eaves and houses up to 800 people. They are either round or square in plan and enclose a central open courtyard where the ancestral hall, private school and stage are placed.

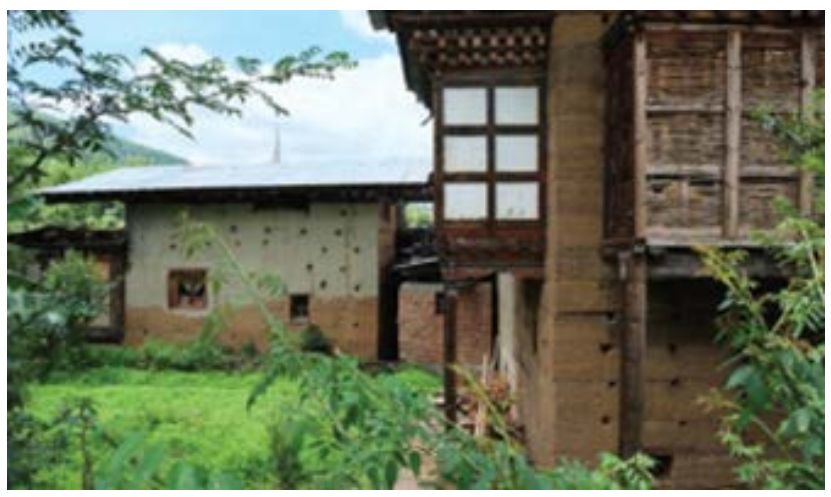

Figure 13. Rammed earth wall [16]

Sun concluded that the vernacular housing is climate responsive in terms of material, passive techniques and local environment. The researchers also mentioned that Siheyuan is the type of dwelling form which exists in all regions of China, with regional variations according to the regional climate.

Wongphyat [16] has done a research on Bhutanese dwellings: sustaining the state of wellbeing-ness. In the research, the author studied and explored the ways of sustaining the traditional Bhutanese dwellings. The researcher selected Shari village, of Paro Dzongkhag, as the study area considering the abundance of natural and cultural resources and biodiversity. The village consists of eighty households of which seventeen households are selected for the study. According to the research, the construction techniques and materials used are found to be same for all the houses. The houses are two storied buildings with either an open or an enclosed attic and rammed earth walls and wooden components make up the main structural materials (Figure 13). Unlike the cement and tiled floorings of today, the houses used wooden planks for flooring and traditionally wooden shingles for roofing for construction. However, due to changes in past practice, it has been replaced by corrugated galvanized iron sheets as roofing materials. Wongphyat concluded that modernization and urbanization in the country has led to the decline of the growth of its traditional houses.

The researcher felt that by mass community participation can only help to achieve the goal of sustaining the state of wellbeing-ness of the traditional Bhutanese dwellings in today's changing times.

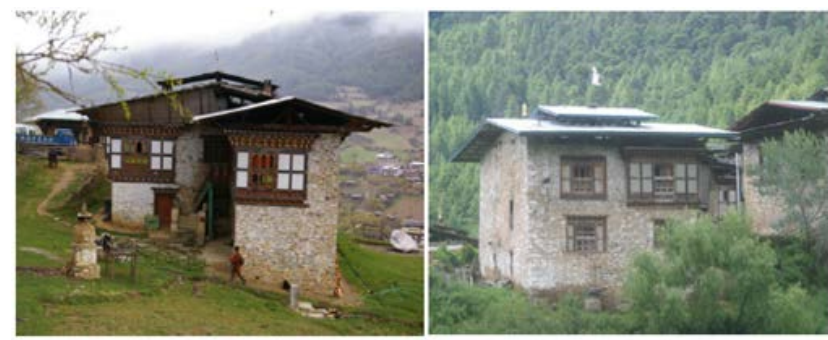

(a)

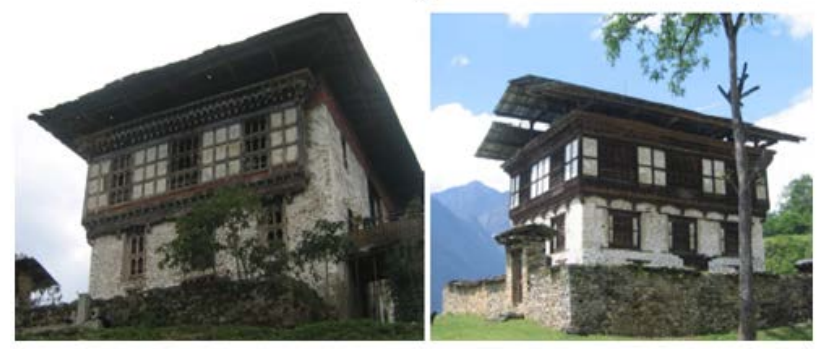

(b)

Figure 14. Traditional houses in eastern Bhutan, (a) Bumthang and (b) Lhuntse [3]

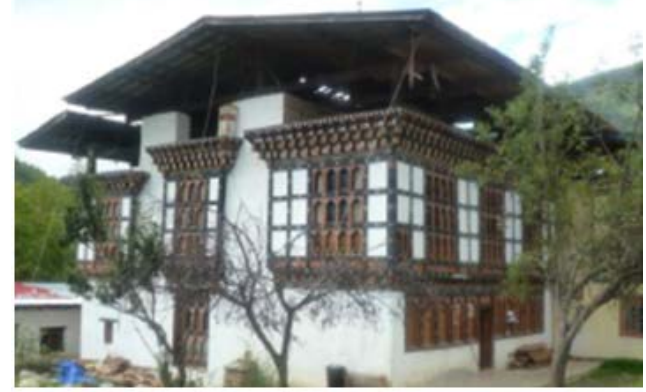

(a)

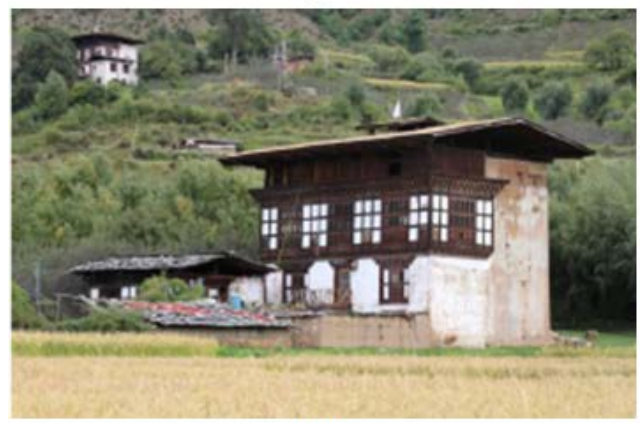

(b)

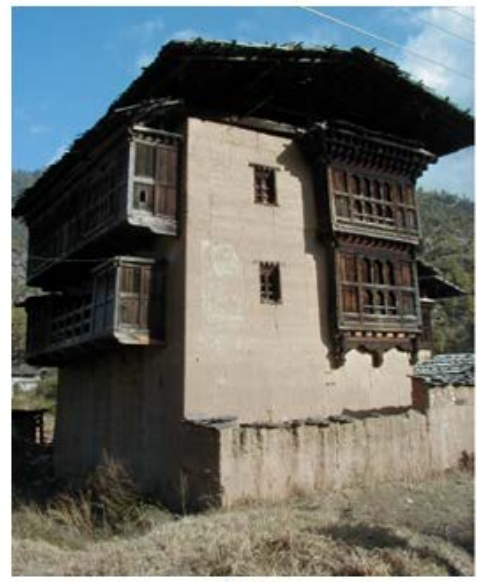

(c)

Figure 15. (a)-(b) Traditional houses in western Bhutan (Paro), (c) Traditional houses in western Bhutan (Thimphu) [3] 


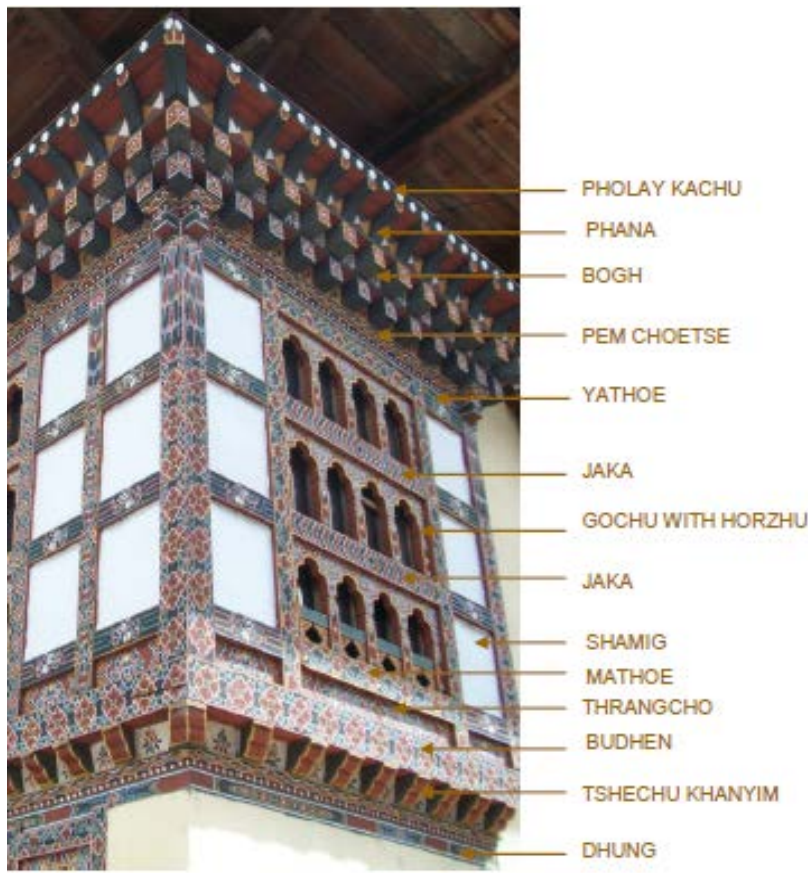

Figure 16. Components of a typical Rabsel [3]

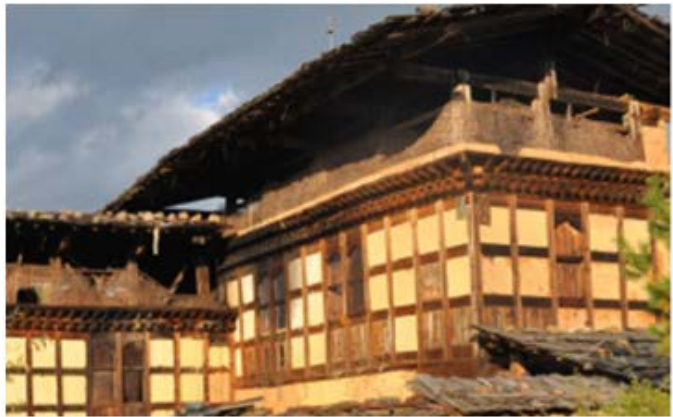

(a)

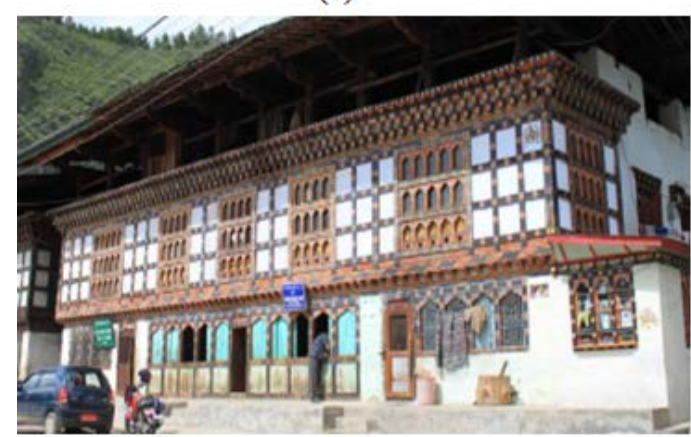

(b)

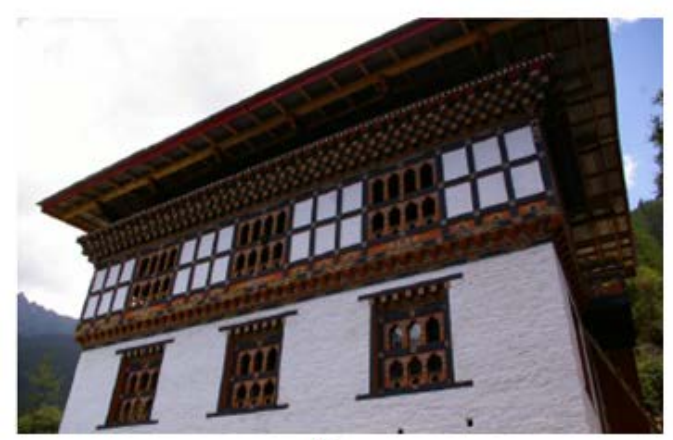

(c)

Figure 17. (a) Rabsel Go-cham, (b) Parop rabsel, and (c) Byelgo rabsel [3]
The Ministry of Works and Human Settlement (MoWHS), Royal Govt. of Bhutan [3] explains the features of the vernacular architecture of Bhutan in the Bhutanese architectural guidelines and also insisted to follow the guidelines while designing the contemporary houses in Bhutan. In the guidelines, it is mentioned that in traditional Bhutanese architecture, there is generally no planning and designing done on paper before a structure is built. The design and construction of buildings is managed by the local carpenters (zow) and masons (Dozop). The best examples of traditional Bhutanese architecture can be seen in Dzongs (fortresses), Lhakhangs (temples), Goenpas (monasteries), Chortens (stupas). The construction materials and techniques are the same for the traditional dwellings throughout the country with only minor variations in the type of Rabsels (projected windows) and material used for the wall construction from region to region (Figure 14 (a)-(b) and Figure 15 (a)-(c). Stone masonry is mainly used in the eastern part while rammed earth construction is usually found in western part of Bhutan.

In the guidelines, it is mentioned that the Rabsel (projected window) (Figure 16) is one of the most important feature of the traditional Bhutanese architecture which adds sophistication to a Bhutanese house due to its beautiful and striking nature. The various types of rabsels are shown in Figure 17 (a)-(c), Figure 18 (a)-(c) and Figure 19 (a)-(b).

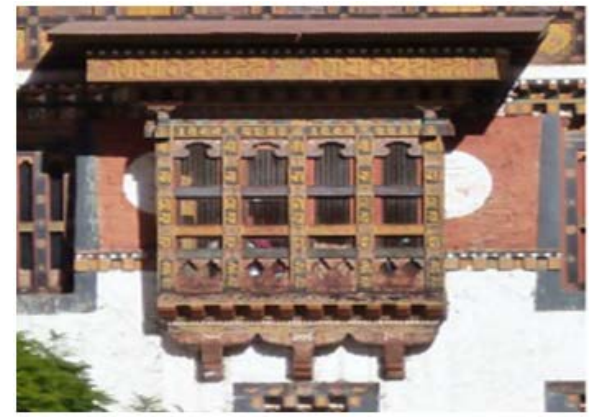

(a)

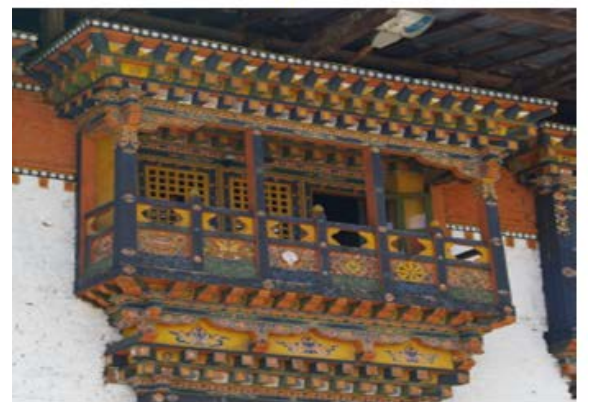

(b)

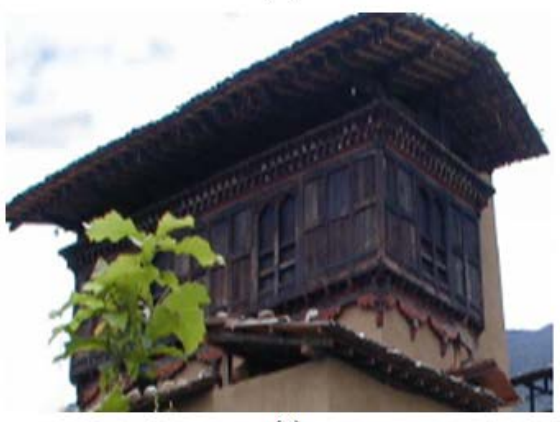

(c)

Figure 18. (a) Nyimchu rabsel, (b) Gomang rabsel, and (c) Gyesargo Rabsel [3] 


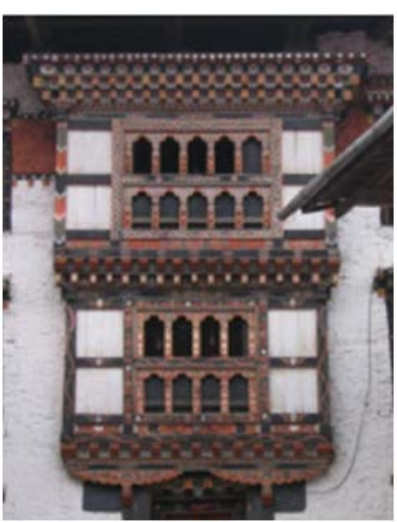

(a)

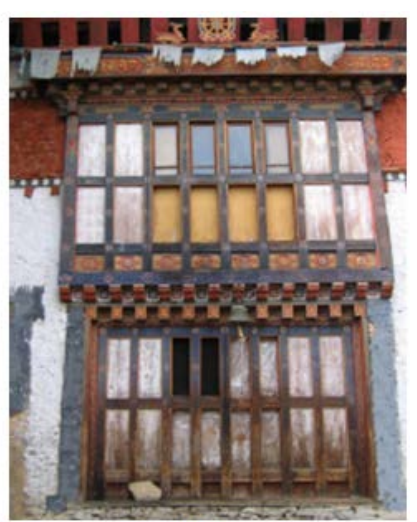

(b)
Figure 19. (a) Lingo rabsel in Bumthang and (b) Lobur rabsel [3]

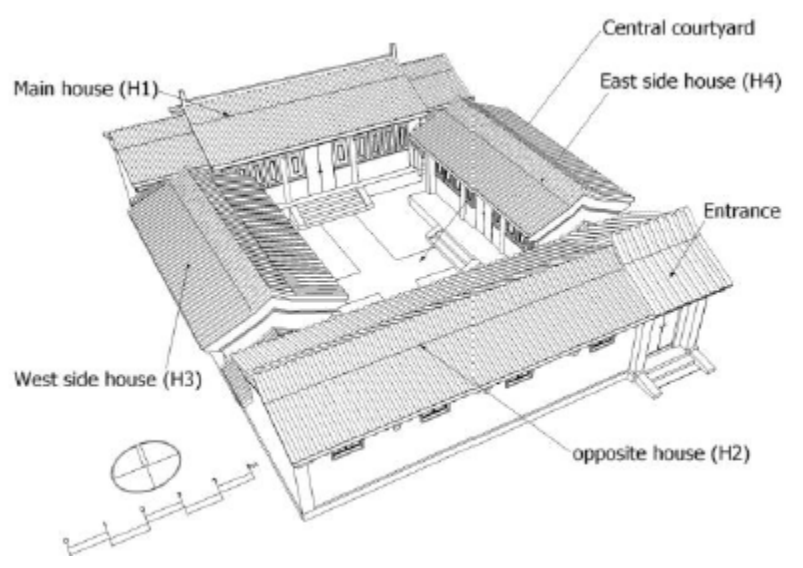

Figure 20. Typical layout of Beijing courtyard house [17]

Shi and NG [17] studied on climatic design in Chinese vernacular courtyard house settlement. Moreover, they also extensively studied the wind environment of the houses with primary focus on understanding how the same architectural form adapt to the wind environment in different seasons with opposite weather conditions. In the initial part of the study, they have taken a basic courtyard house form in Beijing as shown in Figure 20 and studied the wind environment in the courtyard house. In the research, they further conducted a parametric study of the effects of width to length ratio (W/L) and north building height to south building height ratio $(\mathrm{H} 1 / \mathrm{H} 2)$ on the wind environment in courtyard houses. Shi and NG conclude that the energy consumption by the buildings is on the rise and due to which it is becoming important for the architects to study and apply the climate responsive strategies of the vernacular courtyard settlements in contemporary architecture.

Truong [18] has put forth learnt lessons from climatic response in Vietnamese vernacular house. In the study, the researcher analyzed the eight cases of vernacular houses of Vietnam, viz. Giap's house, Quan Nhan house, Khu's house, Di-Luan house, Ngu's house, Anh's house, My-Hoa house and a typical house, located in rural lowland of the north and central Vietnam. From the study, researcher categorized the findings as housing layout and building design, material usage, gardens and landscape, roof and water conservation. In conclusion, Truong explains how the results from this study give us lessons in various areas (site planning, building design, materiality, landscaping and water conservation) which can be used in developing the contemporary residential architecture towards sustainability.

\section{Conclusion}

From the present review, it can be stated that religion and culture play an important role in shaping the architecture of a country. From the elaborate paintings on the façade of traditional Bhutanese houses to the elevated floor of Thai houses, cultural and religious beliefs of the Buddhist people are strongly reflected in the architecture. All the countries which have been chosen in the present study shows that due to somewhat similar religion and culture, they share similar architectural features in their traditional dwellings, such as elevated floor, high pitched roof, choice of building material, removable exterior wooden staircase, rectilinear forms, etc. It also may be put forth that the climate of the region plays an important role in the architectural features of the traditional dwellings.

\section{References}

[1] Aris, M., and Hutt, M., Bhutan: aspects of culture and development, Paul Strachan-Kiscadale Ltd., Gartmore, Scotland, 1994.

[2] Chitranukroh, J., and Buranakarn, V. "Sentiment in traditional Thai architecture", Nakhara: Journal of Environmental Design and Planning, 1, 117-132, 2006.

[3] Ministry of Works and Human Settlement, Bhutanese Architecture Guidelines, Royal Government of Bhutan, Thimpu, Bhutan, 2014, 48-134.

[4] Vinh, L. T., "Frame structure of Vietnam traditional wooden architecture", in $5^{\text {th }}$ International Proceedings on Structural Analysis on historical constructions, Macmillan India Ltd., 368-374.

[5] Kretz, E. (2009) Traditional housing in northern Laos - wood preferences and impact on the forest diversity, Thesis, Swedish University of Agricultural Sciences, 12-46.

[6] Satoshi, Y., “The Tradition of Wooden Architecture in Japan”, 2006, pdf, Available:

http://www.nara.accu.or.jp/elearning/2006/tradition.pdf, 1-6.

[7] Virginia, N., Moe, D. S., Hlaing, U., "Kayin Traditional Houses in Myanmar", International Journal of Emerging Technology and Advanced Engineering, 3(11), 27-36, 2013.

[8] Sun, F., "Chinese climate and vernacular dwellings”, Buildings, 3, 143-172.

[9] D’Ayala, D., and Bajracharya, S. S. R., Traditional Nawari house in Kathmandu valley, 2004, pdf, Available: http://www.worldhousing.net/WHEReports/wh100103.pdf.

[10] Chen, R., Kang, E., Ji, X., Yang, J. and Yang, Y., “Cold Regions in China”, Cold Regions Science and Technology, 45(2), 95-102, 2006.

[11] Department of Urban Development and Housing, Traditional architecture guidelines, Royal Government of Bhutan, Thimpu, Bhutan, 17-18.

[12] Sdei, A. Thermal comfort in the Traditional Japanese house, Cambridge UK, 2005, pdf, Available: http://www.inive.org/members_area/medias/pdf/Inive\%5CIAQVE C2007\%5CSdei.pdf.

[13] Shah, R. S., "Regionalism and Nepalese Architecture". in Proceedings of the Regional Seminar sponsored by the Aga Khan Award for Architecture, 1985, 95-100.

[14] Choi, D., "Scales and Meanings of Architecture and Urbanism in Sapporo," in Proceedings of the International Conference on East Asian Architectural Culture, 2006, 2, 275-281.

[15] Antarikananda, P., Douvlou, E., and McCartney, K., "Lessons from traditional architecture: Design for a climatic responsive contemporary house in Thailand”, in 23rd Conference on Passive and Low Energy Architecture, 2006. 
[16] Wongphyat, W., "Bhutanese dwellings: Sustaining the state of wellbeing-ness", Nakhara: Journal of Environmental Design and Planning, 11, 111-124, 2015.

[17] Shi, Y., and NG, E., "The climatic design in Chinese vernacular courtyard house settlement; A wind environmental simulation", in $30^{\text {th }}$ International PLEA Conference, 2014; 1-8.
[18] Truong, N. H. L., "Lessons from climatic response in Vietnamese vernacular house”, Journal of Civil Engineering and Environmental Technology, 1(2), 41-46, 2014. 